\title{
Removal of organic dye in the hybrid photocatalysis/membrane processes system
}

\author{
${ }^{1}$ Joanna Grzechulska-Damszel, Antoni W. Morawski \\ Szczecin University of Technology, Institute of Chemical and Environment Engineering, Pułaskiego 10, 70-322 Szczecin, \\ Poland, Tel. +48 (91) 449-4730; Fax: +48 (91) 449-4686; e-mail: joanna@ps.pl \\ ${ }^{1}$ corresponding author
}

\begin{abstract}
The removal of azo dye Acid Red 18 in hybrid photocatalysis/membrane processes systems was investigated. The photocatalytic reactions were conducted in the reactor with photocatalyst suspended in the solution. The reaction solution was recirculated through the ultrafiltration system. A commercially available titanium dioxide (Aeroxide ${ }^{\circledR}$ P25, Degussa, Germany) was used as a photocatalyst. The solution after the photocatalytic/UF reaction was applied as the feed for the membrane distillation process. The changes of various parameters, including the concentration of the dye, $\mathrm{pH}$ and the conductivity of the solution, TOC and TDS content were analyzed during the process.

It was found that azo dye Acid Red 18 could be successfully decolourised in the hybrid photocatalysis/UF system. The catalyst particles were retained in the feed solution by means of the ultrafiltration membrane so the obtained permeate was free of $\mathrm{TiO}_{2}$. The application of ultrafiltration together with the photocatalytic process results in the separation of photocatalyst from the treated solution but does not give the complete removal of organic matter from the reaction mixture. Membrane distillation applied with the permeate after the photocatalysis/UF process as a feed gives a complete separation of TOC from the treated solution and the obtained product is practically pure water.
\end{abstract}

Keywords: titanium dioxide, photocatalysis, membrane processes, organic dyes, hybrid systems.

Presented at VII Conference Wasteless Technologies and Waste Management in Chemical Industry and Agriculture, Międzyzdroje, 12 - 15 June, 2007.

\section{INTRODUCTION}

Water pollution due to toxic organic compounds is a serious problem nowadays since the legal regulations concerning disposal of chemicals into the natural environment are more and more restrictive. This problem concerns also the colored wastewaters. The methods of purification of colored wastewaters can be generally divided in two groups: chemical (reduction, oxidation, ion exchange, neutralization) or physical (precipitation, adsorption, filtration, reverse osmosis) methods and biological methods. One of the chemical methods that may be applied for color wastewater purification is photocatalysis. Photocatalytic reactions allow in many cases a complete degradation of organic pollutants in very small and not noxious species, without using chemicals, avoiding sludge production and its disposal ${ }^{1-7}$. Photocatalysis is the only advanced chemical oxidation process that uses dissolved oxygen and a heterogeneous catalyst to carry out a photodriven oxidation at an ambient temperature. The dominant catalyst investigated in the literature is titanium dioxide, $\mathrm{TiO}_{2}$.

The photocatalytic process can be operated with the photocatalyst suspended in the reaction medium or immobilized on various supports ${ }^{8-11}$. These configurations have both advantages and disadvantages. Photocatalytic reactors with the suspended catalyst give a much better contact between the photocatalyst and the dissolved impurities comparing to the reactors with the immobilized catalyst. However, in this case the step of separation of the catalyst is necessary, which increases the overall costs of the process. Although $\mathrm{TiO}_{2}$ shows high photocatalytic activity, the problem of separation of its particles emerges in the practical applications. The photocatalyst particles are usually so small that gravitational separation is not possible.

Pressure driven membrane processes, like microfiltration (MF), ultrafiltration (UF), nanofiltration (NF) and reverse osmosis (RO) have found numerous applications in water treatment and wastewater purification for many years ${ }^{12}$. The possibilities of the utilization of membrane techniques for the separation of the photocatalyst have also been tested recently.

Hybrid processes combining photocatalysis and membrane techniques are an interesting alternative for conventional methods of water and wastewater purification ${ }^{\mathbf{1 3 - 2 1}}$. The positive aspects of coupling of these processes enable the retention of photocatalyst in the reaction medium by means of membrane, control of the retention time of the particles in the reactor, realization of the continuous process with a simultaneous separation of the products from the reaction medium. The other application could be the membrane separation of decomposition products after the photocatalytic reaction in the reactors with the immobilized catalyst bed.

The aim of the presented work was the investigation on the possibility of the application of the hybrid photocatalysis/membrane distillation system for the removal of azo dye AR18 and the products of its decomposition from water. The changes of various parameters, including the concentration of dyes, $\mathrm{pH}$ and the conductivity of the solution, TOC and TDS content were analyzed during the process. 


\section{MATERIALS AND METHODS}

A commercially available titanium dioxide (Aeroxide ${ }^{\circledR}$ P25, Degussa, Germany) was used as a photocatalyst. According to the manufacturer, the specific surface area of the catalyst is ca. $50 \mathrm{~m}^{2} / \mathrm{g}$ and the average primary particle size is $21 \mathrm{~nm}$.

Acid Red 18 (AR18), produced by Chemical Factory „Boruta-Kolor” (Poland), was used as a model azo-dye. Selected dye is widely used in textile industry. The chemical structure of AR18 is presented in Figure 1. AR18 is a monoazo acid dye with a molecular weight of $604.5 \mathrm{~g} /$ mole and the light fastness equals 4 . The initial concentration of dye applied in the experiments was $10 \mathrm{mg} / \mathrm{dm}^{3}$.

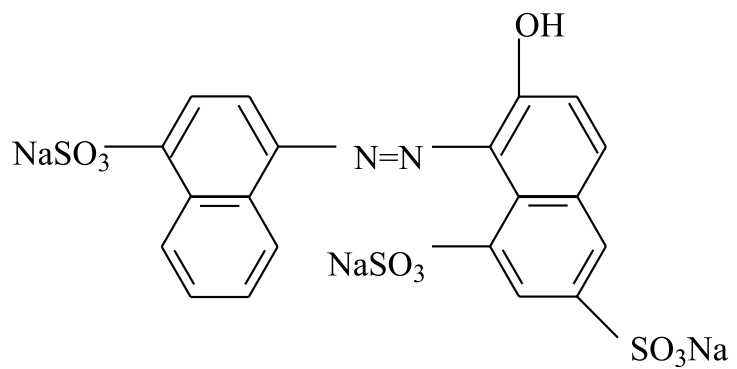

Figure 1. The chemical structure of Acid Red 18

The experiments were conducted in two laboratoryscale systems. Figure 2 presents the apparatus applied in the photocatalysis/UF experiments. The photocatalytic process was conducted using the suspended system and the catalyst particles were retained in the feed solution by means of the ultrafiltration membrane.

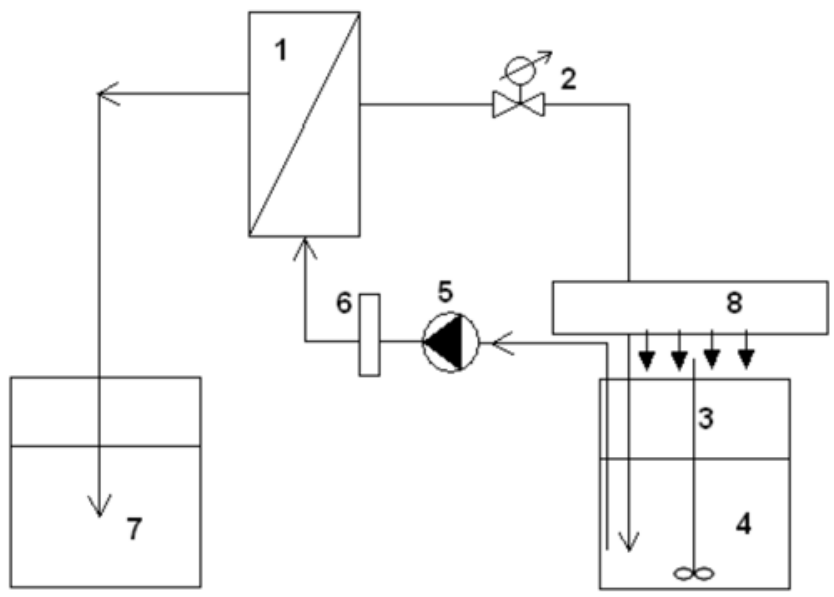

Figure 2. The apparatus applied in the photocatalysis/UF experiments. 1 membrane module, 2 pressure regulator, 3 stirrer, 4 feed tank, 5 suction pump, 6 pressure damper, 7 permeate tank

The main component of the system is the membrane module with a flat polysulfone (PSF) membrane. The membrane was formed by the phase inversion technique using water as the precipitation bath. The casting solution was composed of PSF and dimethylformamide. The membrane was characterized by the determination of the contact angle, porosity, water permeability and the molecular weight-cut off using a dextran solution. The detailed characteristic of the membrane is given elsewhere ${ }^{22}$. The solution of dyes with the suspended photocatalyst was fed into the membrane module from the feed tank using a suction pump. The suspension of the photocatalyst in the feed solution was maintained by a magnetic stirrer. The permeate passing across the membrane was collected in the permeate tank whereas the retentate was recycled to the feed tank. The UF experiments were carried out at a pressure of $0.3 \mathrm{MPa}$ with the feed flow rate of about $90 \mathrm{dm}^{3} / \mathrm{h}$.

The reaction solution was illuminated with a Philips Cleo mercury lamp emitting UV-A light $(\max =355 \mathrm{~nm})$. The UV lamp was placed above the feed tank. The intensity of irradiation was measured with an LB 901 radiometer equipped with the PD204AB (Macam Photometrics) and CM3 (Kipp \& Zonen) external sensors and was equal to $49 \mathrm{~W} / \mathrm{m}^{2}$.

The photocatalytic experiments were conducted until complete discoloration of the solution. After the discoloration of the solution, the permeate was collected (3 $\mathrm{dm}^{3}$ ) and was then applied as a feed for the MD process. The concentration of dyes in the solution was determined by UV-Vis spectrometry at the maximum absorption wavelength $\left(\lambda_{\max }=508 \mathrm{~nm}\right)$ using Jasco V-530 spectrometer in a $5 \mathrm{~cm}$ quartz cells. The samples of the reaction solution were taken for analysis every hour during the first 5 hours of the experiment and then every 5 hours until the solution was decolorized. The total organic carbon (TOC) concentration was measured using the „multi N/C 2000” analyzer (Analytik Jena, Germany). The total dissolved solids (TDS) content, conductivity and $\mathrm{pH}$ of the solution were monitored using Ultrameter $^{\mathrm{TM}}$ 6P (MYRON L COMPANY USA). The colorless solutions were also analyzed in respect of inorganic ions (sulfate, nitrate, nitrite and ammonium).

The reaction solution after discoloration was applied as a feed for the membrane distillation process. The MD process was conducted in the installation presented in Figure 3. The detailed characteristic of the installation and process conditions are given elsewhere ${ }^{21}$. The main component of the system is the capillary module composed of nine polypropylene (PP) Accurel PP S6/2 membranes (Membrana, Wuppertal, Germany). The inlet temperatures of the feed and the distillate were maintained at $343 \mathrm{~K}$ and $293 \mathrm{~K}$, respectively. The volatile compounds present in the warm feed were transferred through the pores of the MD membrane and then condensed/dissolved directly in the cold distillate (distilled water) whereas the non-volatile compounds were retained on the feed side.

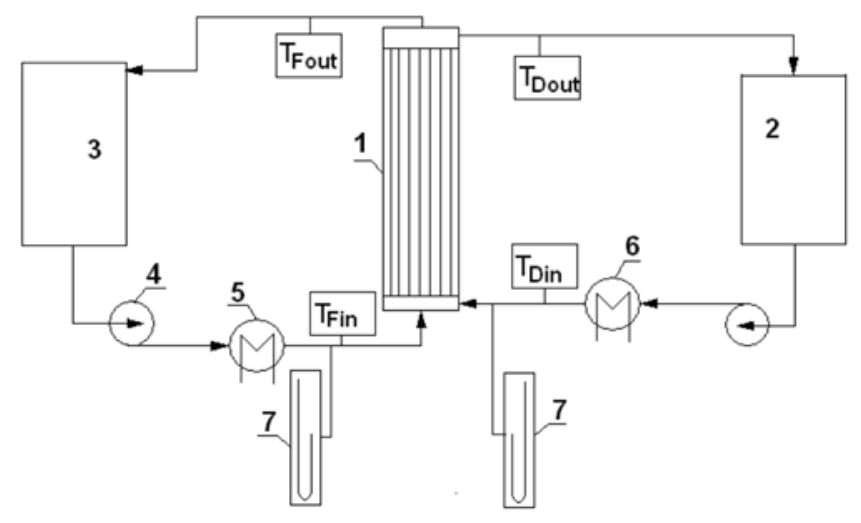

Figure 3. A schematic diagram of the apparatus for MD: (1) membrane module; (2) distillate tank; (3) feed tank $\left(\mathrm{V}=2.9 \mathrm{dm}^{3}\right)$; (4) pump; $(5,6)$ heat exchangers; (7) manometers; (8) UV lamp; TFin, TDin - inlet temperatures of feed and distillate, TFout, TDout - outlet temperatures of feed and distillate 
The feed and the distillate were analyzed in respect of TOC concentration, TDS content, conductivity, $\mathrm{pH}$ values and inorganic ions.

\section{RESULTS AND DISCUSSION}

The experiments of the photocatalytic degradation of AR18 were conducted in the suspension system with the initial dye concentration of $10 \mathrm{mg} / \mathrm{dm}^{3}$. The volume of the treated solution was equal to $4.5 \mathrm{dm}^{3}$. The reaction solution was recirculated through the UF system.

Blank tests conducted in the dark reveal no discoloration of the dyes solutions. The direct photolysis was also negligible. The reactions of the photocatalytic decomposition of dyes were conducted until the solution was colorless.

Figure 4 presents the changes in dye concentration during the photocatalytic process applied with a various concentration of the photocatalyst. For the photocatalyst concentration equal to $0.3 \mathrm{~g} / \mathrm{dm}^{3}$ the solution was colorless after $6 \mathrm{~h}$ of irradiation, whereas for both the smaller $(0.1 \mathrm{~g} /$ $\left.\mathrm{dm}^{3}\right)$ and the higher $\left(0.5 \mathrm{~g} / \mathrm{dm}^{3}\right)$ catalyst dosage the time of discoloration was longer. It took $7 \mathrm{~h}$ to obtain the colorless solution for $\mathrm{TiO}_{2}$ concentration equal to $0.5 \mathrm{~g} /$ $\mathrm{dm}^{3}$ and $8 \mathrm{~h}$ for the concentration of $0.1 \mathrm{~g} / \mathrm{dm}^{3}$.

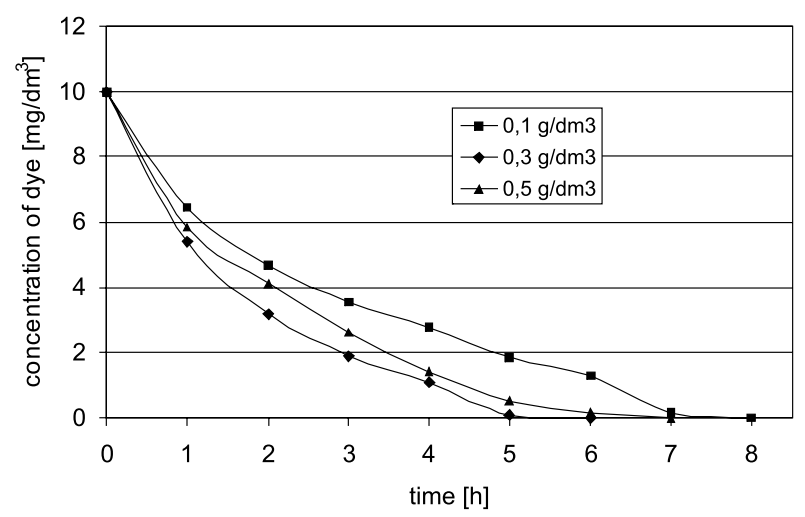

Figure 4. Changes of dye concentration during the photocatalytic process applied with a various concentration of the photocatalyst. Initial dye concentration $-0,1 \mathrm{~g} / \mathrm{dm}^{3} \mathrm{~m}$

The changes in dyes concentrations were monitored by UV/Vis spectroscopy. The discoloration of the solutions during the process is the result of dyes concentration decrease and also the cleavage of $-\mathrm{N}=\mathrm{N}$ - bonds which determine the color of the dyes. Figure 5 presents the spectra of dye solutions recorded during the photocatalytic process. The absorption bands in the visible region are attributed to chromophore groups containing azo unit, whereas absorption in the ultraviolet region is connected with the presence of aromatic rings in dye molecules. As can be seen from Figure 5, decay of both UV and Vis region absorption bands is observed during the photocatalytic process.

Except for the concentration of dyes, the TOC, TDS, conductivity and $\mathrm{pH}$ of the reaction solutions have also been monitored during the photocatalytic process. Changes of these parameters give a wider picture of the degradation process of dyes. The removal of color does not indicate the complete removal of organics from the treated solutions. Decomposition of dyes can lead to smaller

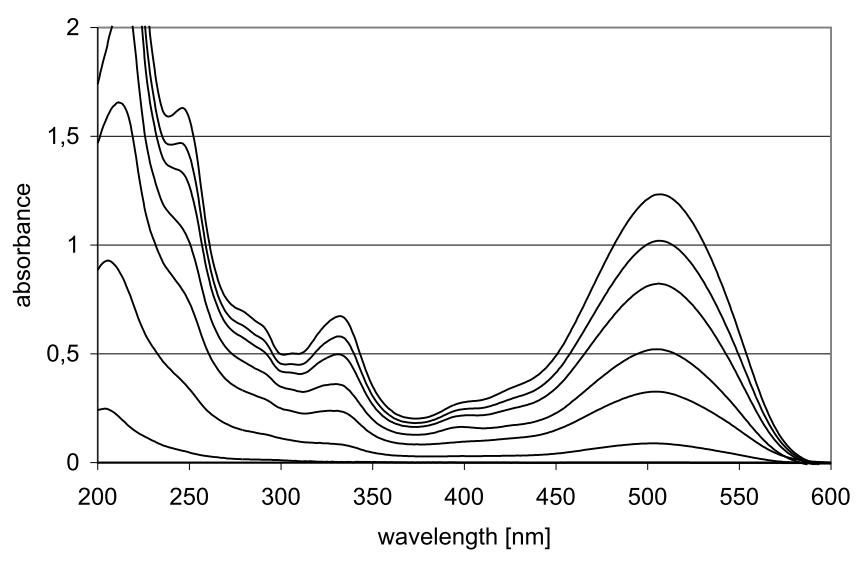

Figure 5. An example spectra of dye solutions recorded during the photocatalytic process. From top to bottom: the initial solution, after $1 \mathrm{~h}$ of illumination, after $2 \mathrm{~h}$ of illumination, after $3 \mathrm{~h}$ of illumination, after $4 \mathrm{~h}$ of illumination, after $5 \mathrm{~h}$ of illumination, after the discoloration ( $6 \mathrm{~h}$ of illumination). The photocatalyst dosage $-0.3 \mathrm{~g} / \mathrm{dm}^{3}$

organic molecules which don't give the coloration but the organic matter is still present in the solution.

TOC analysis revealed the presence of organic carbon in the solution even after the complete discoloration of the solutions (Figure 6). For the catalyst dosage of $0.3 \mathrm{~g} /$ $\mathrm{dm}^{3}$, analysis showed about $73 \%$ of TOC reduction, 41 and $72 \%$ of TOC reduction was obtained for the catalyst dosage of 0.1 and $0.5 \mathrm{~g} / \mathrm{dm}^{3}$, respectively. Although the course of the curves of TOC concentration might indicate the advantage of the application of the highest dosage of photocatalyst $\left(0.5 \mathrm{~g} / \mathrm{dm}^{3}\right)$, the screening effect, resulting in the extension of time of discoloration (see: Figure 4), suggest choosing the amount of the photocatalyst equal to $0.3 \mathrm{~g} / \mathrm{dm}^{3}$ as an optimal catalyst dosage.

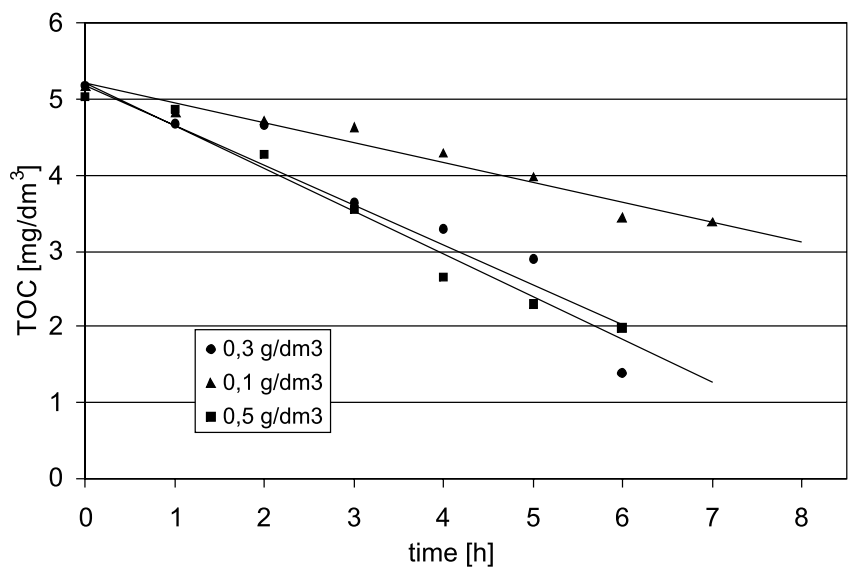

Figure 6. Changes of TOC concentration during the photocatalytic process. Initial dye concentration $-0.1 \mathrm{~g} /$ $\mathrm{dm}^{3}$

The rate of dyes decomposition is also reflected by TDS content and the conductivity of the solution. The TDS parameter indicates all the dissolved species present in the solution, i.e. inorganic ions and all kinds of organic compounds. It was observed that both TDS and conductivity values tend to increase during the process and the values of these parameters were higher with the increasing dosage of the photocatalyst applied.

The $\mathrm{pH}$ value of the solution during the process also provides the information about the course of the photo- 
catalytic reaction. The obtained results show that the $\mathrm{pH}$ value decrease with the time of the process indicating acidification of the solution. This $\mathrm{pH}$ drop results from the oxidation of organics to $\mathrm{CO}_{2}$ and the presence of $\mathrm{H}_{2} \mathrm{SO}_{4}$, since the dyes contain sulfate groups, also the formation of carboxylic acids can take place during the process.

Figure 7 presents the values of TDS, the conductivity and $\mathrm{pH}$ determined during the photocatalysis/UF process for the optimal concentration of $\mathrm{TiO}_{2}\left(0.3 \mathrm{~g} / \mathrm{dm}^{3}\right)$. For the other two dosages of photocatalyst, the tendency of changes was similar.

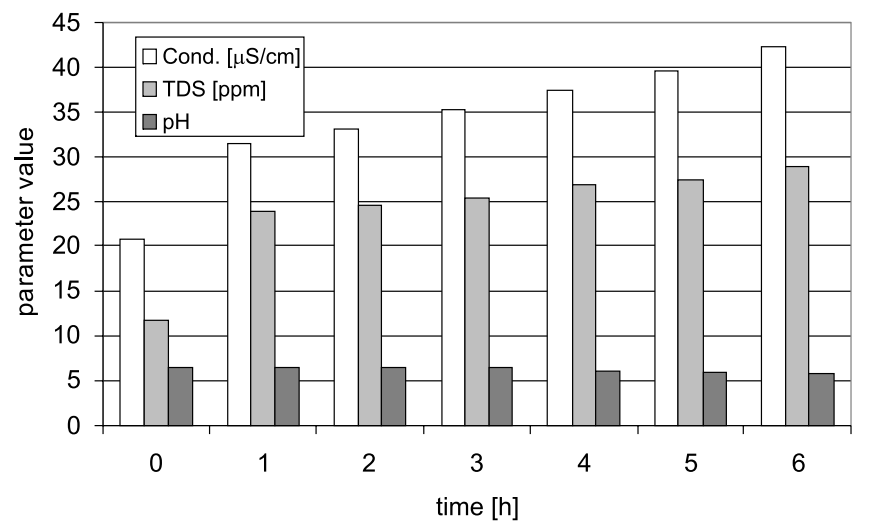

Figure 7. The values of TDS, the conductivity and $\mathrm{pH}$ determined during the photocatalysis/UF process for the optimal concentration of $\mathrm{TiO}_{2}\left(0.3 \mathrm{~g} / \mathrm{dm}^{3}\right)$

The aim of the application of ultrafiltration together with the photocatalytic process was also the separation of $\mathrm{TiO}_{2}$ particles from the treated solution. The obtained results indicated that UF process successfully retains the photocatalyst particles in the feed solution and gives the permeate free of the photocatalyst. During the UF process the permeate flux decrease was observed. This fact is connected with the formation of the filter cake $\left(\mathrm{TiO}_{2}\right.$ particles) onto the membrane surface. The observed fouling of membrane was reversible, since the initial efficiency of the process was recovered after the application of the back-washing with distilled water. The process of back-washing was conducted for 2 min with the rate of delivery of the pump equal to $150 \mathrm{~cm}^{3} / \mathrm{h}$.

Since the photocatalysis/ultrafiltration system did not result in the complete removal of organic matter from the reaction mixture, the permeate after the photocatalysis/ UF process was used as a feed for the MD process. The MD process was conducted for $5 \mathrm{~h}$ with the distillate flux of $336 \mathrm{~m}^{3} / \mathrm{m}^{2} \mathrm{~d}$. The decrease of the distillate flux during the MD process was not observed. Figure 8 presents the values of the parameters analyzed during the MD process (TOC, TDS, the conductivity and $\mathrm{pH}$ ) for the feed and the distillate. The presented results refer to the feed being a permeate after the photocatalysis/UF process with the catalyst dosage of $0.3 \mathrm{~g} / \mathrm{dm}^{3}$. For the other two dosages the tendency of changes was similar. As it can be seen from Figure 8 , the values of the analyzed parameters in the distillate considerably decreased compared to the feed values. The most important is the fact that TOC value in the distillate equals 0 , that is to say that the MD process successfully separates all the organic species presented in the feed.

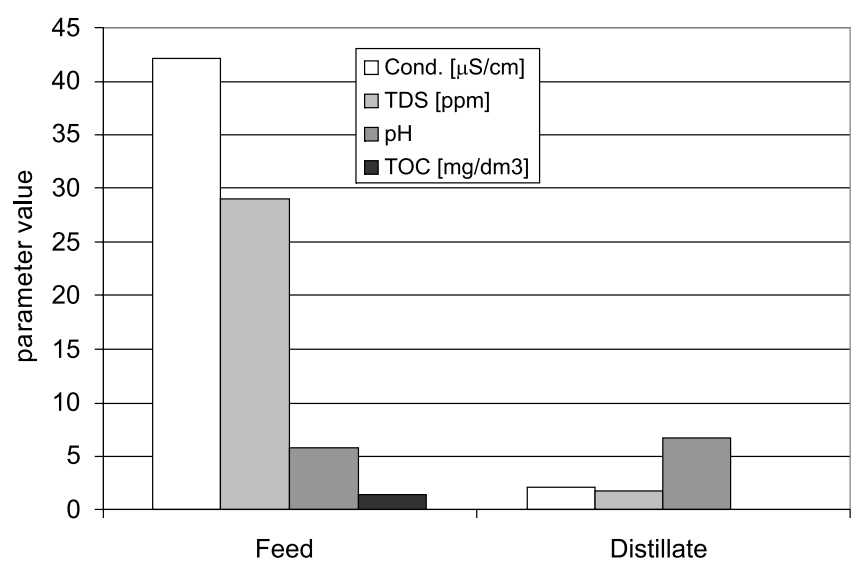

Figure 8. The values of the parameters analyzed during the MD process (TOC, TDS, the conductivity and $\mathrm{pH}$ ) for the feed and the distillate. The feed - the permeate after the photocatalysis/UF process with the catalyst dosage of $0.3 \mathrm{~g} / \mathrm{dm}^{3}$

\section{CONCLUSIONS}

1. The application of hybrid photocatalysis/UF system results in the discoloration of the model dye Acid Red 18 solution in the relatively short time of 6 hours.

2 . The photocatalyst dosage effects the time of discoloration - the best results were obtained for $\mathrm{TiO}_{2}$ concentration equal to $0.3 \mathrm{~g} / \mathrm{dm}^{3}$.

3. Application of ultrafiltration together with photocatalytic process results in the separation of the photocatalyst from the treated solution but does not result in the complete removal of the organic matter from the reaction mixture.

4. Fouling of UF membrane observed during the process is reversible and the maximum permeate flux can be recovered after the back-washing.

5. Membrane distillation applied with the permeate after the photocatalysis/UF process as a feed gives a complete separation of TOC from the treated solution and the obtained product is practically pure water.

\section{ACKNOWLEDGEMENTS}

In the years $2004-2007$ this work has been supported by the grant from The Polish State Committee for Scientific Research, No. 3 T09B 13627.

\section{LITERATURE CITED}

(1) Hoffman M. R., Martin S. T., Choi W., Bahnemann D. W.: Environmental Applications of semiconductor Photocatalysis, Chem. Rev., 1995, 95(1), 69 - 91.

(2) Linsebigler A. L., Lu G., Yates Jr. J. T.: Photocatalysis on $\mathrm{TiO}_{2}$ Surfaces: Principles, Mechanisms, and Selected Results, Chem. Rev., 1995, 95(3), 735 - 758.

(3) Schiavello M., Heterogeneous photocatalysis, John Willey \& Sons, Chichester, New York, Wienheim, Brisbane, Singapore, Toronto, 1997.

(4) Mills A., LeHunte S.: An overview of semiconductor photocatalysis, J. Photochem. Photobiol. A: Chem., 1997, 108(1), 1 - 35.

(5) Herrmann J. -M.: Heterogeneous photocatalysis: fundamentals and applications to the removal of various types of aqueous pollutants, Catal. Today, 1999, 53(1), 115 - 129.

(6) Fujishima A., Rao T. N., Tryk D.: Titanium dioxide photocatalysis, J. Photochem. Photobiol. C: Photochem. Rev., 2000, 1(1), 1 - 21. 
(7) Kaneko M., Okura I.: Photocatalysis. Science and Technology, Kodansha Ltd., Tokyo, Springer-Verlag Berlin Heidelberg, New York, 2002.

(8) Fernández A., Lassaletta G., Jiménez V. M., Justo A., González-Elipe A. R., Herrmann J. -M., Tahiri H., Ait-Ichou Y.: Preparation and characterization of $\mathrm{TiO}_{2}$ photocatalysts supported on various rigid supports (glass, quartz and stainless steel). Comparative studies of photocatalytic activity in water purification, Appl. Catal. B: Environ., 1995, 7(1 - 2), $49-63$.

(9) Grzechulska J., Morawski A. W.: Photocatalytic labyrinth flow reactor with immobilized $\mathrm{P} 25 \mathrm{TiO}_{2}$ bed for removal of phenol from water, Appl. Catal. B: Environ., 2003, 46(2), $415-419$.

(10) Balasubramanian G., Dionysiou D. D., Suidan M. T., Baudin I., Laîné J. -M.: Evaluating the activities of immobilized $\mathrm{TiO}_{2}$ powder films for the photocatalytic degradation of organic contaminants in water, Appl. Catal. B: Environ., 2004, 47(2), 73 - 84 .

(11) Venkata Subba Rao K., Subrahmanyam M., Boule P.: Immobilized $\mathrm{TiO}_{2}$ photocatalyst during long-term use: decrease of its activity, Appl. Catal. B: Environ., 2004, 49(4), $239-249$.

(12) Wintgens T., Melin T., Schäfer A., Khan S., Muston M., Bixio D., Thoeye C.: The role of membrane processes in municipal wastewater reclamation and reuse, Desalination, 2005, 178(1 - 3), 1 - 11 .

(13) Molinari R., Borgese M., Drioli E., Palmisano L., Schiavello M.: Hybrid processes coupling photocatalysis and membranes for degradation of organic pollutants in water, Catal. Today, 2002, 75, $77-85$.

(14) Molinari R., Palmisano L., Drioli E., Schiavello M.: Studies on various reactor configurations for coupling photocatalysis and membrane processes in water purification, $\mathrm{J}$. Membrane Sci. 2002, 206, 399 - 415.

(15) Sopajaree K., Qasim S. A., Basak S., Rajeshwar K.: An integrated flow reactor-membrane filtration system for heterogeneous photocatalysis. Part I. Experiments and modeling of a batch-recirculated photoreactor, J. Appl. Electrochem., 1999, 29(5), 533 - 539.

[16] Sopajaree K., Qasim S. A., Basak S., Rajeshwar K.: An integrated flow reactor-membranefiltration system for heterogenous photocatalysis. Part II. Experiments on the ultrafiltration unit and combined operation. J. Appl. Electrochem., 1999, 29(9), 1111 - 1118.

(17) Molinari R., Mungari M., Drioli E., Di Paola A., Loddo V., Palmisano L., Schiavello M.: Study on a photocatalytic membrane reactor for water purification, Catal. Today, 2000, 55(1 - 2), 71 - 78.

(18) Molinari R., Grande C., Drioli E., Palmisano L., Schiavello M.: Photocatalytic membrane reactors for degradation of organic pollutants in water, Catal. Today, 2001, $67(1-3), 273-279$.

(19) Xi W., Geissen S. -U.: Separation of titanium dioxide from photocatalytically treated water by cross-flow microfiltration, Water Res., 2001, 35(5), 1256 - 1262.

(20) Molinari R., Pirillo F., Falco M., Loddo V., Palmisano L.: Photocatalytic degradation of dye by using a membrane reactor, Chem. Eng. Proc., 2004, 43, 1103 - 1114.

(21) Mozia S., Tomaszewska M., Morawski A. W.: A new photocatalytic membrane reactor (PMR) for removal of azodye Acid Red 18 from water, Appl. Catal. B: Environmental, 2005, 59(1 - 2), 133 - 139.

(22) Mozia S., Tomaszewska M., Morawski A.W.: Removal of azo-dye Acid Red 18 in two hybrid membrane systems employing a photodegradation process, Desalination, 2006, 198,183 - 190 . 